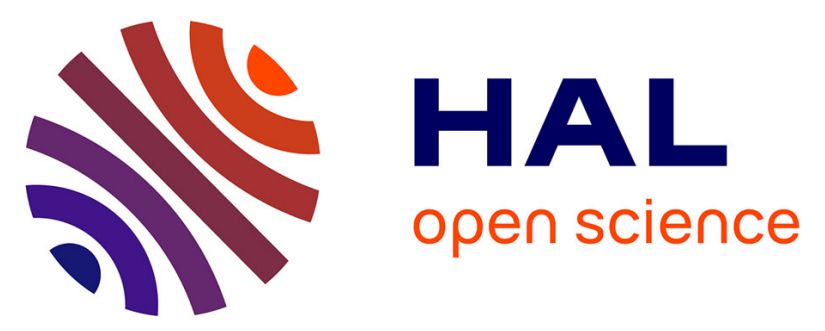

\title{
Impact of the initial microstructure and the loading conditions on the deformation behavior of the Ti17 titanium alloy
}

Houssem Ben Boubaker, Charles Mareau, Yessine Ayed, Guénaël Germain, Albert Tidu

\section{To cite this version:}

Houssem Ben Boubaker, Charles Mareau, Yessine Ayed, Guénaël Germain, Albert Tidu. Impact of the initial microstructure and the loading conditions on the deformation behavior of the Ti17 titanium alloy. Journal of Materials Science, 2019, 55, pp.1765-1778. 10.1007/s10853-019-04014-5 . hal-02397004

\section{HAL Id: hal-02397004 \\ https://hal.science/hal-02397004}

Submitted on 6 Dec 2019

HAL is a multi-disciplinary open access archive for the deposit and dissemination of scientific research documents, whether they are published or not. The documents may come from teaching and research institutions in France or abroad, or from public or private research centers.
L'archive ouverte pluridisciplinaire HAL, est destinée au dépôt et à la diffusion de documents scientifiques de niveau recherche, publiés ou non, émanant des établissements d'enseignement et de recherche français ou étrangers, des laboratoires publics ou privés. 


\title{
Impact of the initial microstructure and the loading conditions on the deformation behavior of the Ti17 titanium alloy
}

\author{
Houssem Ben Boubaker ${ }^{1, *}$ (D), Charles Mareau ${ }^{1}$, Yessine Ayed ${ }^{1}$, Guenael Germain ${ }^{1}$, and \\ Albert Tidu ${ }^{2}$ \\ ${ }^{1}$ Arts et Métiers ParisTech, Campus d'Angers, LAMPA, 2 bd du Ronceray, 49035 Angers Cedex 1, France \\ ${ }^{2}$ Laboratoire d'Étude des Microstructures et de Mécaniques des Matériaux (LEM3), CNRS Université de Lorraine, \\ 57078 Metz Cedex 03, France
}

\begin{abstract}
In this work, the impact of the microstructure and the loading conditions on the mechanical behavior of a $\beta$ rich Ti17 titanium alloy is investigated. For this purpose, two different initial microstructures are considered : (i) a two-phase lamellar $\alpha+\beta$ microstructure and (ii) a single-phase equiaxed $\beta$-treated microstructure. First, compression tests are performed at different strain rates (from $10^{-1}$ to $10 \mathrm{~s}^{-1}$ ) and different temperatures (from 25 to $900{ }^{\circ} \mathrm{C}$ ) for both microstructures. Then, optical microscopy, scanning electron microscopy, EBSD and X-ray diffraction analyses of deformed specimens are carried out. Whatever the loading conditions are, the flow stress of the as-received $\alpha+\beta$ Ti17 is higher than that of the $\beta$-treated Ti17. Also, because of a higher strain-rate sensitivity, the $\beta$-treated Ti17 is less prone to shear banding. At low temperatures (i.e., $T \leq 450{ }^{\circ} \mathrm{C}$ ), the deformation behavior of both the as-received $\alpha+\beta$ and the $\beta$-treated Ti17 is controlled by strain hardening. For the $\beta$-treated Til7 alloy, martensitic transformation is systematically detected in this temperature range. The softening behavior of the as-received $\alpha+\beta$ Ti17 observed at high temper-atures is due to the joint effect of dynamic recrystallization, dynamic transfor-mation, adiabatic heating and morphological texture evolution. For the $\beta$-treated Ti17 alloy, when the temperature exceeds $700{ }^{\circ} \mathrm{C}$, stressstrain curves display a yield drop phenomenon, which is explained by dynamic recrystallization.
\end{abstract}

Address correspondence to E-mail: Houssemeddine.BENBOUBAKER@ensam.eu

https:/ / doi.org/10.1007/s10853-019-04014-5 


\section{Introduction}

Titanium alloys are a high-profile candidate for aerospace applications owing to their excellent corrosion resistance and their high strength-to-weight ratio [1, 2]. Processing of these alloys often involves hot deformation. For this reason, several experimental studies have attempted to quantify the impact of loading conditions on the plastic flow behavior and the microstructure evolution of titanium alloys in both the $\beta$ and $\alpha+\beta$ fields [3-5]. While the lowtemperature behavior of $\alpha+\beta$ titanium alloys is almost exclusively controlled by strain hardening, softening dominates at high temperatures. Depending on the initial microstructure and the loading conditions, the flow softening behavior has been explained by adiabatic heating [6], two-phase HallPetch effect [4], crystallographic texture changes [7], globularization of the lamellar microstructure [8] dynamic transformation [9] and dynamic recrystallization [10]. Also, when the $\beta$-phase volume fraction is important, some titanium alloys exhibit a yield drop phenomenon followed by a steady flow regime at high temperatures [3,5]. According to Kolli and Devaraj [5], the yield drop magnitude depends on both the loading conditions (i.e., strain rate and temperature) and the concentration of alloying elements.

This work focuses on the Ti17 titanium alloy, which is a near- $\beta$ titanium alloy employed for the manufacturing of compressor blades in aero-engines with a service temperature less than $500{ }^{\circ} \mathrm{C}[11,12]$. The mechanical behavior of this alloy in processing conditions is quite complex, mostly because many physical interconnected phenomena are involved (e.g., crystallographic slip, phase transformations [13], recrystallization $[14,15])$. In order to understand the thermo-mechanical behavior of the Ti17 titanium alloy, many experimental studies have been carried out [3, 16-19]. For instance, Liu et al. [8] conducted uniaxial compression tests on a Ti17 alloy with a lamellar microstructure at various temperatures (from 780 to $860^{\circ} \mathrm{C}$ ) and different strain rates (from $10^{-3}$ to $10 \mathrm{~s}^{-1}$ ). For these loading conditions, the deformation behavior was found to be governed by strain softening. For low strain rates, softening was related to the globularization of the lamellar microstructure. For high strain rates (i.e., $10 \mathrm{~s}^{-1}$ ), softening was explained by strain localization.
Similar conclusions have been drawn by Ma et al. [20]. The strain localization process driving to the formation of shear bands has been investigated by Huang et al. [21]. According to the results, dynamic recrystallization occurs in $\beta$ grains in the center region of adiabatic shear bands while dynamic recovery takes place in the surrounding region. The deformation behavior of a sintered Ti17 powder has been investigated by Zhao et al. [19] at different strain rates (from $10^{-3}$ to $1 \mathrm{~s}^{-1}$ ) and different temperatures (from 810 to $920^{\circ} \mathrm{C}$ ). Experimental results have shown that whatever the loading conditions are, flow softening dominates the mechanical behavior for both the $\alpha+\beta$ - and $\beta$-treated microstructures. Zhang et al. [22] investigated the deformation behavior of a heat-treated Ti17 alloy consisting of equiaxed primary $\alpha$-phase grains being embedded in a $\beta$ matrix at room temperature for a low strain rate (i.e $10^{-3} \mathrm{~s}^{-1}$ ). According to the results, basal and prismatic slips were found to be the main deformation modes, and a contribution from twinning was also observed.

In order to study the impact of the initial microstructure on the deformation behavior of titanium alloy, Arab et al. [23] investigated four different heat-treated microstructures of TA15 titanium alloy. Experimental results have shown that both strain-rate sensitivity and adiabatic shear band formation are strongly influenced by the initial microstructure. Also, the martensitic $\alpha^{\prime}$ microstructure exhibited the highest flow stress and hardness level and the lowest fracture strain. The initial microstructure (bimodal microstructure) revealed a good ratio strength-ductility. Jiang et al. [24] have studied the effect of the microstructure heterogeneity on the mechanical behavior of a near $\alpha$ Ti-6Al-2Zr-1Mo-1V alloy. The lamellar microstructure (heat-treated microstructure) was more prone to shear banding than the initial microstructure (equiaxed microstructure). Similar conclusions have been reported by Zhao et al. [25]. In the above studies, little attention has been paid to the impact of the initial microstructure of the Til7 alloy on the deformation behavior. More specifically, in equilibrium conditions, the Ti17 alloy exhibits a twophase $\alpha+\beta$ structure at low temperatures while it is solely composed of $\beta$ grains at high temperatures $\left(T \geq 890^{\circ} \mathrm{C}\right)$. The effect of temperature is therefore often difficult to distinguish from the influence of the initial microstructure since these features are not changed independently. 
This work aims at studying the impact of the initial microstructure on the thermo-mechanical behavior of the Ti17 alloy. For this purpose, two different microstructures are considered: (i) a two-phase lamellar $\alpha+\beta$ microstructure and (ii) a single-phase equiaxed $\beta$ microstructure. The deformation behavior is evaluated from uniaxial compression tests. These tests are performed at different strain rates (from $10^{-1}$ to $10 \mathrm{~s}^{-1}$ ) and different temperatures (from 25 to $900^{\circ} \mathrm{C}$ ) for both microstructures. Also, optical microscopy (OM), scanning electron microscopy (SEM), electron backscatter diffraction (EBSD) and $X$-ray diffraction analyses (XRD) are carried out on deformed specimens to understand the impact of microstructural transformations (e.g., martensitic transformation, recrystallization) on the deformation behavior.

\section{Experimental procedure}

In order to investigate the impact of the initial microstructure on the deformation behavior of the Ti17 titanium alloy, uniaxial compression tests have been conducted using a Gleeble 3500 simulator under vacuum condition $\left(10^{-5}\right.$ bar). Cylindrical specimens, machined from a forged bar, have been used for the compression tests. An axial extensometer has been used to measure the elongation $\Delta L$ while the temperature $T$ has been controlled with a K-type thermocouple. Prior to each test, two graphite sheets have been placed between the anvils and the upper and lower faces of compression specimens to reduce friction and favor electrical conduction. The compression tests have been carried out with a constant nominal strain rate, ranging from 0.1 to $10 \mathrm{~s}^{-1}$, up to an axial strain of $50 \%$. The initial test temperature is comprised between 25 and $900^{\circ} \mathrm{C}$. The axial true stress $\sigma$ and the axial logarithmic strain $\varepsilon$ are computed from the elongation $\Delta L$ and the axial force $F$ with the following relations:

$$
\begin{aligned}
& \sigma=\frac{F}{A_{0}}\left(1+\frac{\Delta L}{L_{0}}\right) \\
& \varepsilon=\ln \left(1+\frac{\Delta L}{L_{0}}\right)
\end{aligned}
$$

where $A_{0}$ (respectively, $L_{0}$ ) is the initial gauge area (respectively, gauge length). The above estimations of the axial true stress $\sigma$ and true strain $\varepsilon$ rely on the assumptions that (i) the volume remains constant during deformation and (ii) the strain and stress fields are homogeneous. While this approach is reasonable for low strains, it may yield inaccurate results, especially at high temperatures and high strains, for which significant barreling is often observed. In this case, the strain, the strain rate and the temperature vary compared to the nominal test conditions across the specimen.

The chemical composition of the Ti17 alloy is given in Table 1. The as-received $\alpha+\beta$ microstructure is shown in Fig. 1. For this condition, the Ti17 alloy displays a lamellar microstructure composed of $67 \%$ of $\alpha$-phase lamellae and $33 \%$ of $\beta$-phase matrix. The average grain size is about $1 \mathrm{~mm}$ while the thickness of $\alpha$ lamellae does not exceed $0.8 \mu \mathrm{m}$. As shown in Fig. 1, $\alpha$ lamellae are randomly oriented.

To characterize the mechanical behavior of the asreceived $\alpha+\beta$ Ti17, specimens are heated to the compression temperature with a heating rate of $100{ }^{\circ} \mathrm{C} / \mathrm{s}$. The temperature is then held constant for 5 $\mathrm{s}$ before compression. The compression test is finally performed, and specimens are rapidly cooled to room temperature with a compressed air jet.

Vickers hardness measurements, with a load of 500 $\mathrm{g}$, have been performed to evaluate the initial hardness of the $\alpha+\beta$ microstructure, which is about $340 \pm 6 \mathrm{HV}_{0.5}$. The corresponding standard deviation is relatively low, which indicates that the Vickers hardness is not much sensitive to the crystallographic orientation.

To understand the impact of the microstructure on the deformation behavior of Ti17, a second microstructure, which is solely composed of equiaxed $\beta$ grains, has been obtained (see Fig. 2 ). The procedure used to obtain the $\beta$-treated Til7 is as follows: The specimen is first heated from room temperature to $920^{\circ} \mathrm{C}$ (i.e., above the $\beta$ transus temperature) with a rate of $20^{\circ} \mathrm{C} / \mathrm{s}$. Temperature is maintained for $10 \mathrm{~min}$, and the specimen is rapidly cooled down to the test temperature. As before, the compression test is performed and the specimen is finally quenched to room temperature. It should be noticed that the above heat treatment does not affect the average size of $\beta$ grains. Vickers hardness measurements, with a load of $500 \mathrm{~g}$, have been performed to evaluate the initial hardness of the $\beta$-treated microstructure, which is about $306 \pm 5 \mathrm{HV}_{0.5}$.

The above procedures have been selected to avoid phase transitions so that, for both the as-received $\alpha+$ 
Table 1 Chemical composition of the Ti17 titanium alloy

Figure 1 Metallographic observation (OM and SEM) of the as-received $\alpha+\beta$ Ti17 microstructure.

\begin{tabular}{llllll}
\hline $\mathrm{Ti}$ & $\mathrm{Al}$ & $\mathrm{Mo}$ & $\mathrm{Cr}$ & $\mathrm{Zr}$ & $\mathrm{Sn}$ \\
\hline $82.68 \mathrm{wt} \%$ & $4.96 \mathrm{wt} \%$ & $4.01 \mathrm{wt} \%$ & $4.07 \mathrm{wt} \%$ & $2.06 \mathrm{wt} \%$ & $2.02 \mathrm{wt} \%$ \\
\hline
\end{tabular}
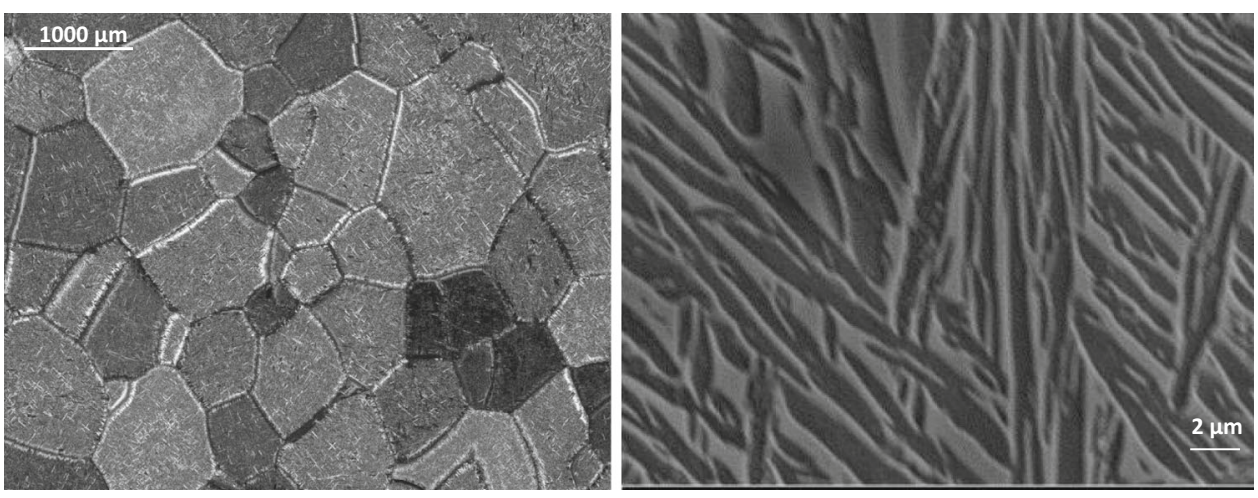

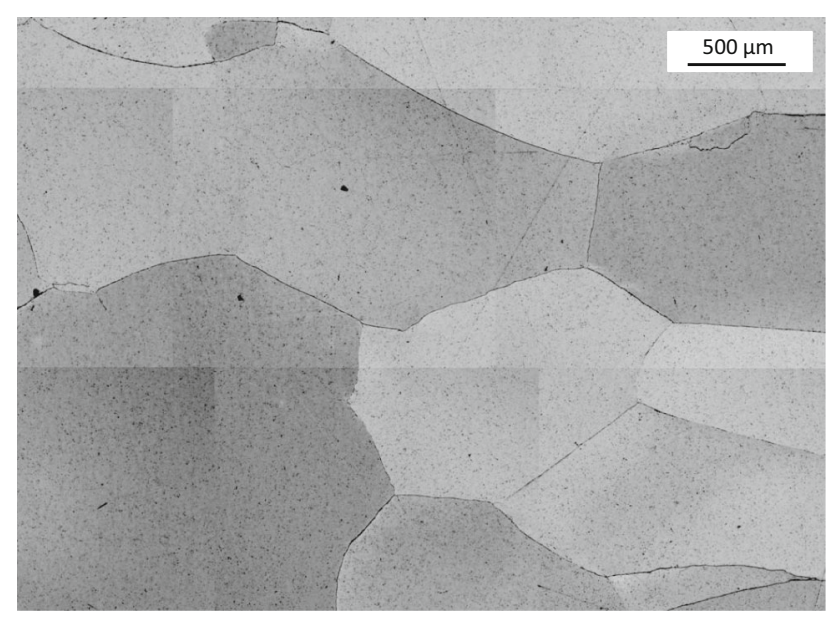

Figure 2 Metallographic observation of the $\beta$-treated Ti17 after solution treatment.

$\beta$ Ti17 and the $\beta$-treated Ti17, the microstructure at the beginning of the compression test is the same for all test conditions. Also, these procedures allow limiting temperature gradients, the maximum temperature difference being inferior to $20^{\circ} \mathrm{C}$ at the beginning of a compression test.

In this work, each compression test has been repeated at least three times under identical conditions. A correct repeatability is generally observed. Indeed, for a given axial strain, flow stress variations prior to fracture between tests do not exceed $6 \%$. Also, in this work, the effect of the crystallographic texture change in the region where the hardness measurements have been taken was not taken into account.

\section{Mechanical behavior}

\section{As-received $\alpha+\beta$ Ti17 alloy}

The stress-strain curves obtained for the as-received $\alpha+\beta$ Ti17 alloy at different temperatures and strain rates are plotted in Fig. 3. As shown in Fig. 3, regardless of the loading conditions, the stress-strain curves of the deformed $\alpha+\beta$ Ti17 alloy do not exhibit a steady flow behavior. More specifically, for high temperatures $\left(T \geq 650^{\circ} \mathrm{C}\right)$, the initial yielding is immediately followed by a continuous softening. A similar trend has been observed for this alloy by [26] and [19]. At the opposite, for low temperatures $\left(T \leq 450{ }^{\circ} \mathrm{C}\right)$, a significant increase in the flow stress is observed. In the intermediate temperature range $\left(550 \leq T \leq 600^{\circ} \mathrm{C}\right)$, the as-received $\alpha+\beta$ Ti17 alloy displays a two-stage behavior with a hardening stage followed by a softening stage. For strain rates of $1 \mathrm{~s}^{-1}$ and $10 \mathrm{~s}^{-1}$, the flow stress at $600^{\circ} \mathrm{C}$ is lower than the one obtained at $550{ }^{\circ} \mathrm{C}$. As for $0.1 \mathrm{~s}^{-1}$, the flow stresses at $550{ }^{\circ} \mathrm{C}$ and $600^{\circ} \mathrm{C}$ are quite similar. This result is likely explained by the fact that (i) the temperature elevation is higher at $550{ }^{\circ} \mathrm{C}$ and (ii) shear banding occurs earlier at $550^{\circ} \mathrm{C}$. Both phenomena would contribute to softening.

Also, because an elevated temperature provides dislocations with sufficient thermal energy to overcome short-range obstacles [27], an increase in temperature is associated with a decrease in the flow stress and an increase in the fracture strain for a given strain rate. 

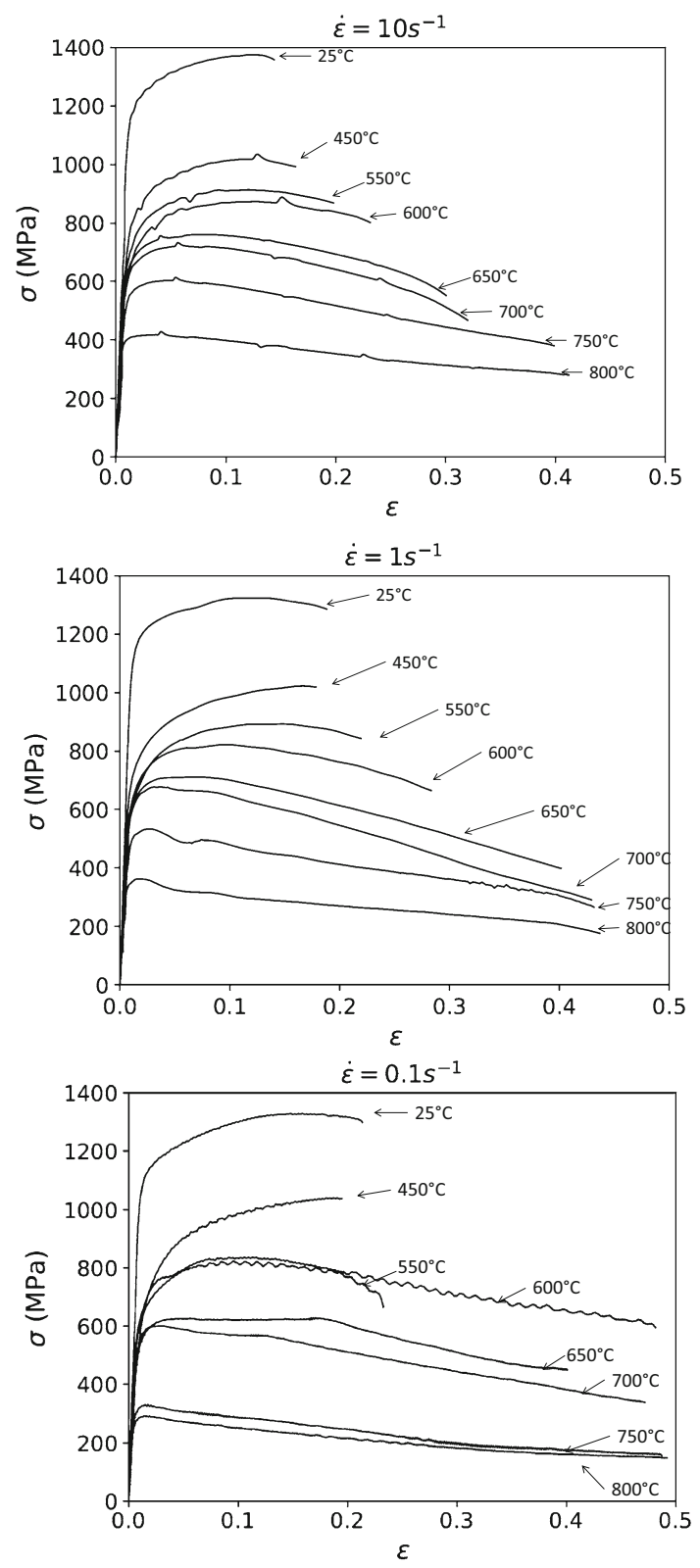

Figure 3 Stress-strain curves for the compression tests carried out on the as-received $\alpha+\beta$ Ti17 alloy at temperatures ranging from 25 to $800^{\circ} \mathrm{C}$ and different strain rates: $10 \mathrm{~s}^{-1}, 1 \mathrm{~s}^{-1}$ and 0.1 $\mathrm{s}^{-1}$.

\section{$\beta$-Treated Ti17 alloy}

The stress-strain curves for the $\beta$-treated Ti17 alloy at various strain rates and temperatures are shown in Fig. 4. For low temperatures $\left(T \leq 450^{\circ} \mathrm{C}\right)$, the behavior is controlled by strain hardening. At high temperatures $\left(T \geq 700^{\circ} \mathrm{C}\right)$, the $\beta$-treated Ti17 alloy exhibits a yield drop phenomenon, which is particularly visible for the lowest strain rate $\left(\dot{\varepsilon}=0.1 \mathrm{~s}^{-1}\right)$.
This specific yielding behavior has already been reported in many $\beta$ titanium alloys (e.g., Ti40 [28] and Ti-20V-4Al-1S [29]). The yield drop is reduced when the strain rate is increased. A similar trend has already been observed by $\mathrm{Wu}$ et al. [30] when investigating the high-temperature behavior of the Ti-55 alloy. Also, for a strain rate of $0.1 \mathrm{~s}^{-1}$, some short-period flow stress oscillations are observed at high temperatures. Those oscillations are only related to greater noise when recording low forces on the Gleeble equipment.

\section{Comparison}

The flow stresses, obtained for an axial strain of $10 \%$, are given in Fig. 5 for both microstructures. Whatever the loading conditions are, the flow stress of the $\beta$ treated Ti17 alloy is inferior to that of the as-received $\alpha+\beta$ Ti17 alloy. This difference is explained by (i) the higher fraction of $\beta$-phase in the $\beta$-treated alloy, which is known to be the softer phase, and (ii) the important increase of the mean free path of dislocations due to the dissolution of the $\alpha$-phase during the solution treatment used for the preparation of $\beta$ treated Ti17 specimens.

For given axial strain $\varepsilon$ and temperature $T$, the strain-rate sensitivity coefficient $m$ is defined by [31]:

$m=\left.\frac{\partial \log \sigma}{\partial \log \dot{\varepsilon}}\right|_{\varepsilon, T}$

where $\dot{\varepsilon}$ is the axial strain rate. The strain-rate sensitivity coefficient $m$ has been evaluated for an axial strain of $10 \%$ from the experimental stress-strain curves. The corresponding results are plotted as a function of temperature in Fig. 6. While the progression of the strain-rate sensitivity coefficient with temperature is moderate for $T \leq 650{ }^{\circ} \mathrm{C}$ for both microstructures, a significant increase is observed for high temperatures. In comparison with the as-received $\alpha+\beta$ Ti17 alloy, the $\beta$-treated alloy is found to be more strain-rate sensitive in the investigated temperature range. The higher strain-rate sensitivity of BCC metals is due to the specific core structure of screw dislocations. In contrast to other structures, the core of screw dislocations is spread onto three different slip planes for BCC metals, which renders difficult the glide of screw dislocation segments. The movement of screw dislocations therefore proceeds by the formation of kinks, resulting in a higher strainrate sensitivity [32]. 

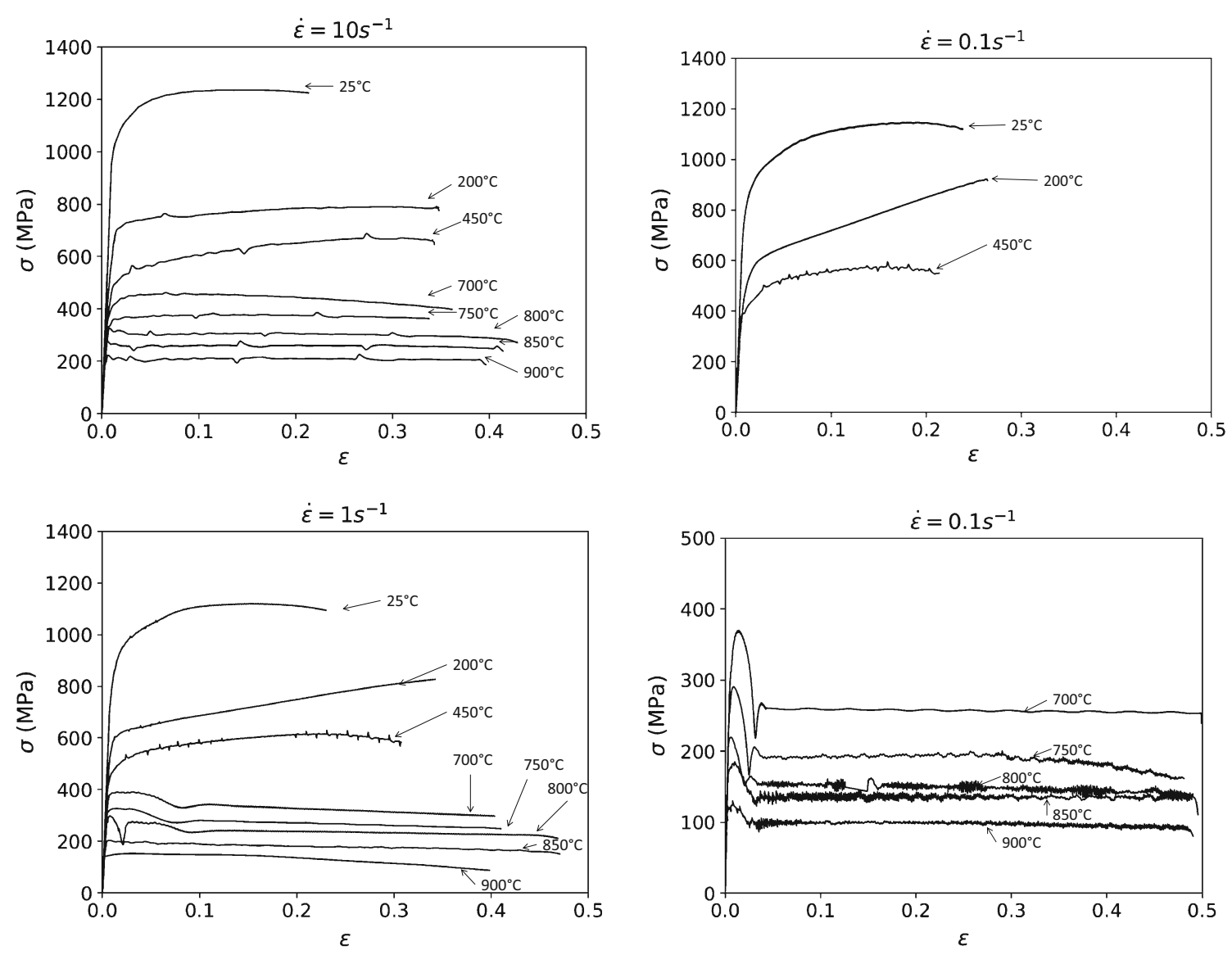

Figure 4 Stress-strain curves for the compression tests carried out on the $\beta$-treated Ti17 alloy ranging from 25 to $900{ }^{\circ} \mathrm{C}$ and strain rates ranging from 0.1 to $10 \mathrm{~s}^{-1}$.

Vickers hardness measurements have been performed with a $500 \mathrm{~g}$ load along the radial direction of deformed specimens starting from the center. The corresponding results are shown in Fig. 7 for both microstructures. For all deformation temperatures, the final hardness of the as-received $\alpha+\beta$ Ti17 alloy is superior to that of the $\beta$ - treated alloy, which confirms that the former is harder than the latter.

\section{Discussion}

\section{As-received $\alpha+\beta$ Ti17 alloy}

For low temperatures $\left(T \leq 450{ }^{\circ} \mathrm{C}\right)$, the mechanical behavior of the as-received $\alpha+\beta$ microstructure is controlled by strain hardening. Because the final hardness is systematically higher than the initial hardness, strain hardening remains significant for both low and high temperatures. Since the average size of $\alpha$ lamellae remains unchanged during deformation, the increase in hardness is likely explained by the augmentation of the dislocation density. The softening behavior observed for both intermediate and high temperatures cannot therefore be explained from a recovery mechanism. To better understand the softening mechanism, some metallographic observations of deformed specimens have been performed.

According to the results, several phenomena are expected to contribute to the flow softening behavior. First, for high temperatures $\left(T \geq 650^{\circ} \mathrm{C}\right)$, some recrystallized grains are observed in the central part of compression specimens (see Fig. 8). As shown in Table 2, which provides a summary of the loading conditions leading to dynamic recrystallization, recrystallized grains are preferably formed at high temperatures and low strain rates. As discussed by Sakai and Jonas [33], the elimination of dislocations caused by the migration of high-angle boundaries contributes to softening. Second, as illustrated by Fig. 9, $\alpha$-phase lamellae are rotated toward the radial 



Figure 5 Flow stresses for an axial strain of $10 \%$ for the $\alpha+\beta$ Ti17 alloy (a) and the $\beta$-treated Ti17 alloy (b).

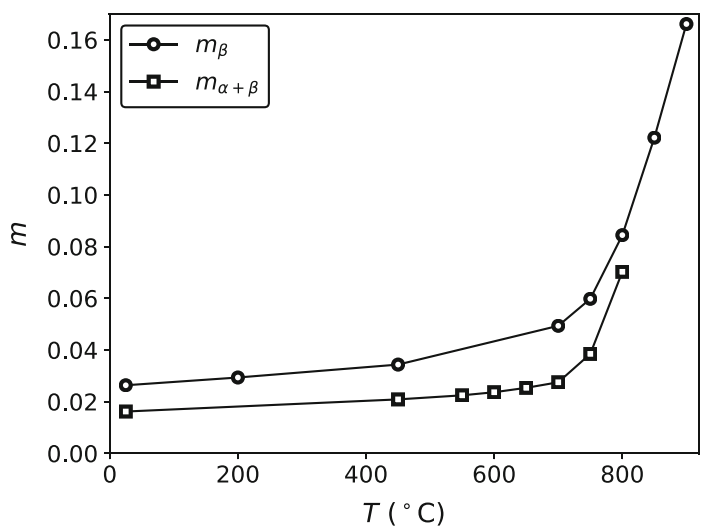

Figure 6 Variation in the strain-rate sensitivity coefficient $m$ of the as-received $\alpha+\beta$ Ti17 and the $\beta$-treated Ti17 alloy as a function of temperature.

direction of compression specimens. This morphological texture evolution results in the formation of a layered microstructure, $\alpha$-phase lamellae being perpendicular to the compression axis. The formation of such a layered microstructure, for which the yield stress is controlled by the soft phase, also participates to the softening behavior. Local kinking of $\alpha$-phase
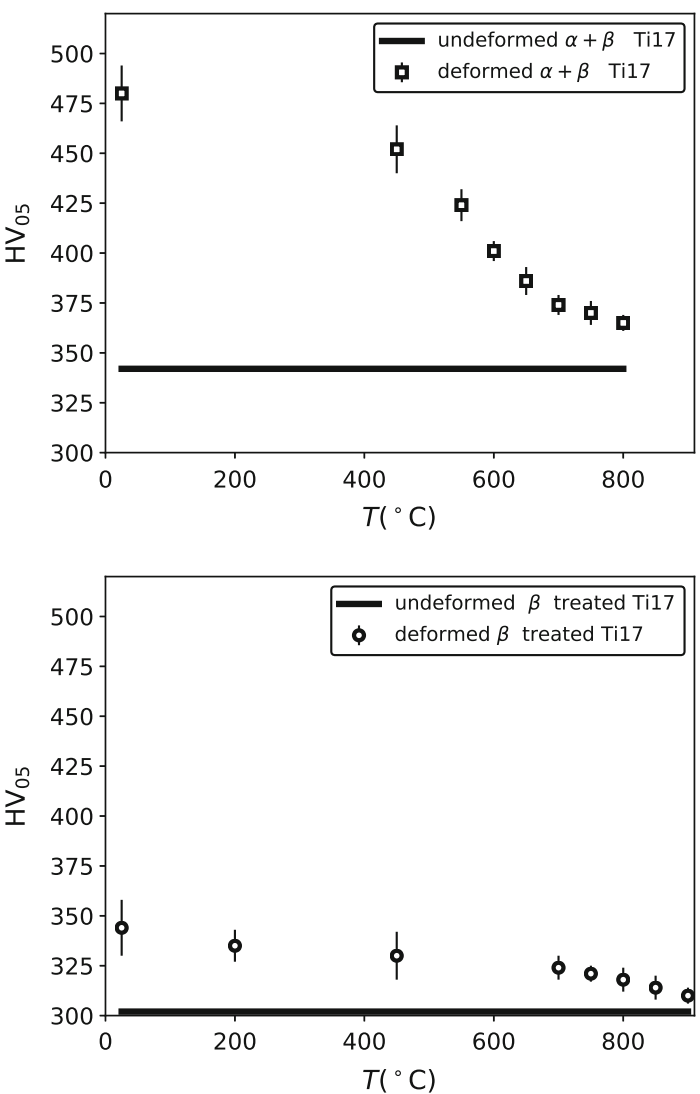

Figure 7 Evolution of the final Vickers hardness (after deformation) of the as-received $\alpha+\beta$ and $\beta$-treated Ti17 alloy as a function of temperature. The hardness of the undeformed material is indicated with a horizontal line.

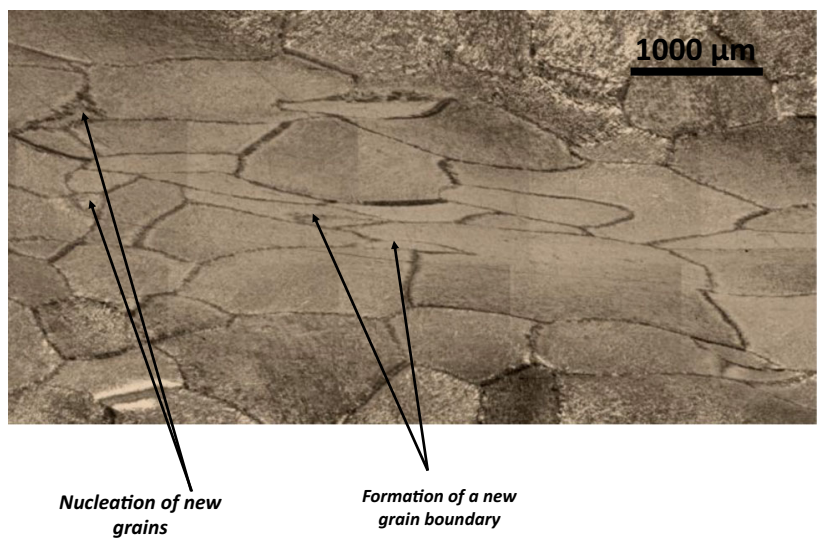

Figure 8 OM observation of recrystallized grains in the center of deformed specimen at a strain rate of $1 \mathrm{~s}^{-1}$ and a temperature of $800^{\circ} \mathrm{C}$.

lamellae is also sometimes observed after deformation. A similar phenomenon has been observed by $\mathrm{Li}$ et al. [34] in a near- $\alpha$ titanium alloy. Third, the temperature rise $\Delta T$ resulting from adiabatic heating 

occurrence of adiabatic shear banding $(\bullet)$ and recrystallization (o) during uniaxial compression of the asreceived $\alpha+\beta$ Ti17 alloy
Table 2 Summary of the

\begin{tabular}{llll}
\hline$T\left({ }^{\circ} \mathrm{C}\right)$ & \multicolumn{3}{l}{ Strain rate $\left(\mathrm{s}^{-1}\right)$} \\
\cline { 2 - 4 } & 0.1 & 1 & 10 \\
\hline 25 & $\bullet$ & $\bullet$ & $\bullet$ \\
450 & $\bullet$ & $\bullet$ & $\bullet$ \\
550 & $\bullet$ & $\bullet$ & $\bullet$ \\
600 & $\bullet$ & $\bullet$ & $\bullet$ \\
650 & $\circ$ & $\bullet$ & $\bullet$ \\
700 & $\circ$ & $\circ$ & $\bullet$ \\
750 & $\circ$ & $\circ$ & $\circ$ \\
800 & $\circ$ & $\circ$ & $\circ$ \\
\hline
\end{tabular}

during compression tests is given in Table 3 for the as-received $\alpha+\beta$ Ti17 alloy. The temperature increase is particularly significant for high strain rates and/or low temperatures. As a result, compression tests are not carried out under strict isothermal conditions so that a thermal contribution to softening cannot be excluded in this range. Finally, a contribution of dynamic transformation to softening has been discussed by Semiatin et al. [35] for the TA6V alloy. In the present case, the $\alpha \rightarrow \beta$ phase transformation has been detected in the central region of compression specimens when temperature exceeds $600^{\circ} \mathrm{C}$. Because the $\beta$-phase is softer than the $\alpha$-phase, this mechanism likely provides a contribution to the softening behavior.
Table 3 Summary of the temperature increase $\left(\Delta T^{\circ} \mathrm{C}\right)$ after uniaxial compression of the as-received $\alpha+\beta$ Ti17 alloy for an axial strain of $15 \%$

\begin{tabular}{lrrr}
\hline$T\left({ }^{\circ} \mathrm{C}\right)$ & \multicolumn{3}{l}{ Strain rate $\left(\mathrm{s}^{-1}\right)$} \\
\cline { 2 - 4 } & 0.1 & 1 & 10 \\
\hline 25 & 60 & 69 & 80 \\
450 & 48 & 57 & 74 \\
550 & 42 & 50 & 57 \\
600 & 34 & 42 & 51 \\
650 & 16 & 36 & 46 \\
700 & 8 & 17 & 36 \\
750 & 6 & 12 & 23 \\
800 & 2 & 7 & 13 \\
\hline
\end{tabular}

For some loading conditions, a strain localization phenomenon, leading to the formation of an adiabatic shear band (ASB), is observed. The loading conditions leading to the formation of an ASB are presented in Table 2. ASBs are preferably formed for high strain rates and low temperatures, when dynamic recrystallization does not occur. The influence of temperature on the formation of ASBs is likely related to the change in strain-rate sensitivity, an increasing strain-rate sensitivity being known to reduce the critical strain necessary for the formation of ASBs [36].

As shown in Fig. 10, adiabatic shear bands are oriented with an angle of $\pm 45^{\circ}$ with respect to the
Figure 9 SEM observations of a Ti17 specimen after deformation at a strain rate of $1 \mathrm{~s}^{-1}$ and a temperature of $750{ }^{\circ} \mathrm{C}$ : alignment of $\alpha$-phase lamellae and kinking of $\alpha$ phase lamellae. The compression axis is vertical.
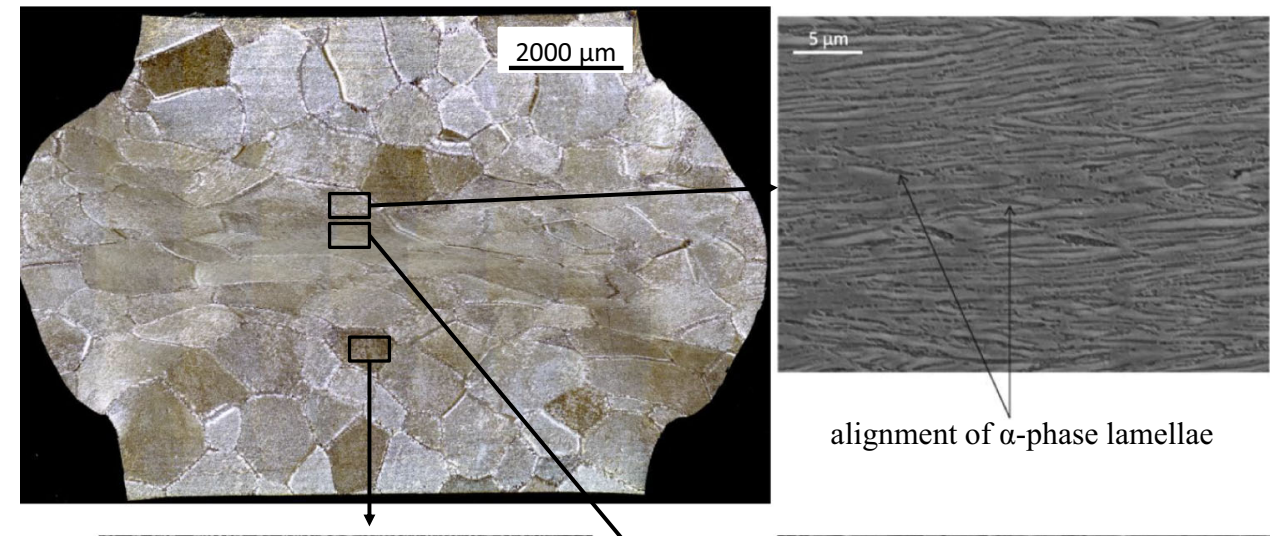

alignment of $\alpha$-phase lamellae
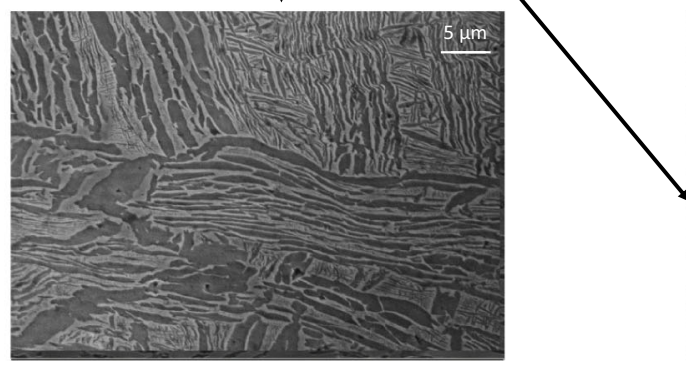

kinking of $\alpha$-phase lamellae 
Figure 10 Metallographic observations of the $\alpha+\beta$ Ti17 specimen deformed at a strain rate of $10 \mathrm{~s}^{-1}$ and a temperature of $700^{\circ} \mathrm{C}$.

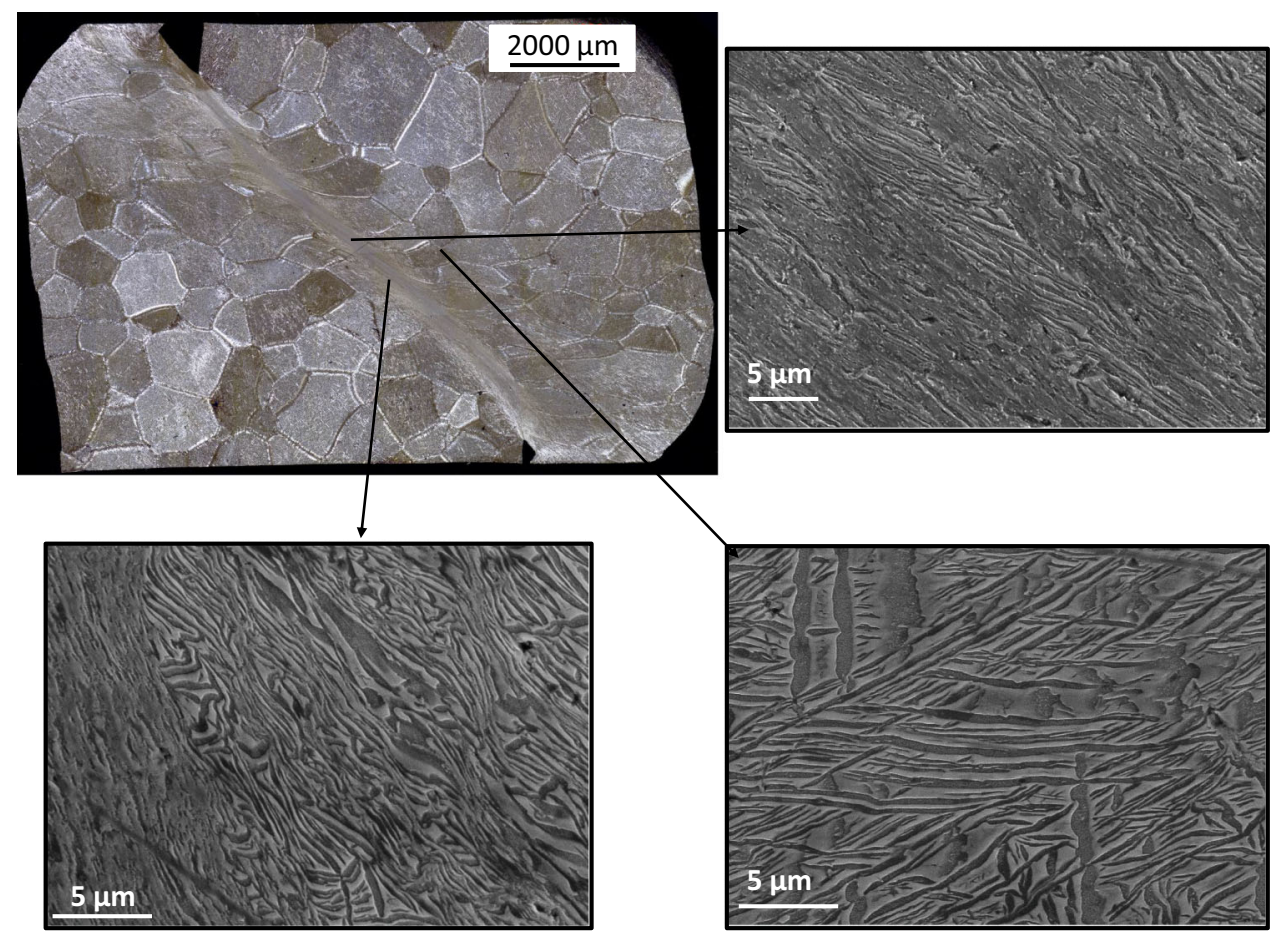

compression direction. As illustrated by Fig. 10, within an ASB, $\alpha$-phase lamellae are severely deformed and rotated toward the shear direction. In agreement with the results of Ma et al. [31], some $\alpha$ phase lamellae are also fragmented or kinked. At the opposite, away from an ASB, the microstructure remains almost unchanged, which indicates that plastic deformation is almost exclusively accommodated by ASBs.

Some micro-hardness measurements have been performed on deformed specimens of the $\alpha+\beta$ Ti17 alloy in both the interior and the exterior of an ASB for different conditions. As shown in Fig. 11, the hardness in the interior of an ASB is inferior to that in the exterior region. This phenomenon is likely explained by the significant local temperature increase associated with the formation of an ASB during a compression test. Thus, because shear banding is accompanied by thermal softening, a contribution of shear banding to the overall softening behavior cannot be excluded [37].

\section{$\beta$-Treated Ti17 alloy}

In the high temperature range $\left(T \geq 700{ }^{\circ} \mathrm{C}\right)$, the behavior of the $\beta$-treated Ti17 alloy is largely impacted by dynamic recrystallization. Indeed, according to the EBSD analyses of deformed $\beta$ - treated specimens, some recrystallized $\beta$ grains, which are preferably formed at triple junctions and along grain boundaries, are observed at high temperatures (see Fig. 12). The loading conditions leading to dynamic recrystallization are listed in Table 4 . For these conditions, the yield drop phenomenon is systematically detected. As suggested by Sandstrom et al. [38] and Rezaee et al. [39], the yield drop phenomenon is therefore likely due to dynamic recrystallization. Specifically, the growth of recrystallized grains, with a low dislocation content, is associated with a rapid decrease in the yield stress.

For low temperatures $\left(T \leq 450{ }^{\circ} \mathrm{C}\right)$, martensitic transformation takes place during the deformation process of $\beta$-treated specimens (see Fig. 13a). According to Grosdidier et al. [40] and Nwobu [41], the sequence leading to the formation of the hexagonal $\alpha^{\prime}$-phase involves an intermediate stage where the $\beta$-phase first transforms into the orthorhombic $\alpha^{\prime \prime}$ phase (i.e., $\beta \rightarrow \alpha^{\prime \prime} \rightarrow \alpha^{\prime}$ ). In the present case, neither high-resolution EBSD nor XRD analyses have allowed detecting the presence of the intermediate $\alpha^{\prime \prime}$-phase.

Also, some twins, with a misorientation of $\approx 87^{\circ}$ around $\langle\overline{1120}\rangle$, have been observed in the interior of $\alpha^{\prime}$ lamellae (see Fig. 13d). This indicates that the $\{10 \overline{1} 2\}\langle\overline{1} 011\rangle$ twinning systems are activated during the deformation of the martensitic phase. 
Figure 11 Evolution of the final Vickers hardness across an adiabatic shear band for different strain rates and temperatures.

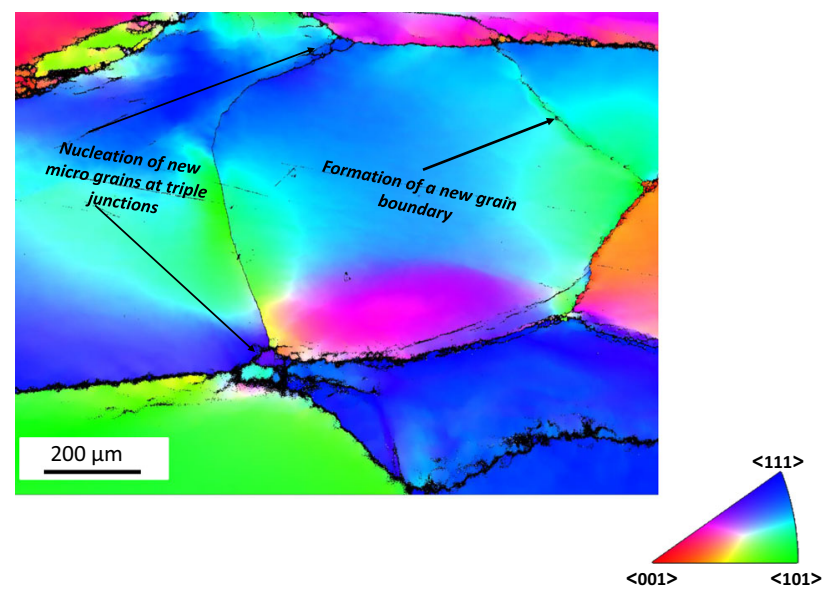

Figure 12 EBSD map taken in the center of a $\beta$-treated Ti17 specimen deformed at $800^{\circ} \mathrm{C}$ and $0.1 \mathrm{~s}^{-1}$.

According to metallographic observations of deformed specimens, an increase in the strain rate and/or a decrease in the temperature is associated with an increase in the volume fraction of $\alpha^{\prime}$ martensite. A similar trend has been observed by Ma et al. [42] and Paradkar and Kamat [43]. The effect of the temperature on the occurrence of the martensitic transformation has been reported by Hamada et al. [44]. Furthermore, $\alpha^{\prime}$ martensite lamellae are found to
Table 4 Summary of the occurrence of adiabatic shear banding (•) and recrystallization $(\mathrm{o})$ during uniaxial compression of the $\beta$ treated Ti17 alloy

\begin{tabular}{llcc}
\hline$T\left({ }^{\circ} \mathrm{C}\right)$ & \multicolumn{2}{l}{ Strain rate $\left(\mathrm{s}^{-1}\right)$} \\
\cline { 2 - 4 } & 0.1 & 1 & 10 \\
\hline 25 & & & $\bullet$ \\
200 & & & $\bullet$ \\
450 & & & \\
700 & $\circ$ & $\circ$ & $\circ$ \\
750 & $\circ$ & $\circ$ & $\circ$ \\
800 & $\circ$ & $\circ$ & $\circ$ \\
850 & $\circ$ & $\circ$ & $\circ$ \\
900 & $\circ$ & $\circ$ & $\circ$ \\
\hline
\end{tabular}

nucleate preferably at grain boundaries and propagate across $\beta$ grains. Similar observations have been reported by Wei et al. [45] in a near- $\beta$ titanium alloy.

During a deformation process, the martensitic transformation results in the formation of additional interfaces, which contribute to strain hardening. A similar trend has been observed for the $\beta_{C e z}$ alloy by Grosdidier et al. [40] and Grosdidier and Philippe [46]. In addition, some grains are filled with $\alpha^{\prime}$ martensite lamellae while some other grains do not show any evidence of martensitic transformation. As shown in Fig. 13e, the occurrence of martensitic transformation results in an important hardness 
Figure 13 a Metallographic observation of an adiabatic shear band in a deformed $\beta$ treated Ti17 specimen at a strain rate of $10 \mathrm{~s}^{-1}$ and a temperature of $25^{\circ} \mathrm{C} . \mathbf{b} \alpha^{\prime}$ martensite. c XRD pattern obtained with a $\mathrm{Cu} \mathrm{K} \alpha$ radiation. $\mathbf{d}$ Observation of a $\{10 \overline{1} 2\}\langle\overline{1011}\rangle$ extension twin in a martensitic domain in a $\beta$ treated Ti17 specimen that has been deformed at $25^{\circ} \mathrm{C}$ and $10 \mathrm{~s}^{-1}$. The Atex software [48] has been used for the post-processing of EBSD data. e Evolution of the final Vickers hardness on a line perpendicular to the compression axis.

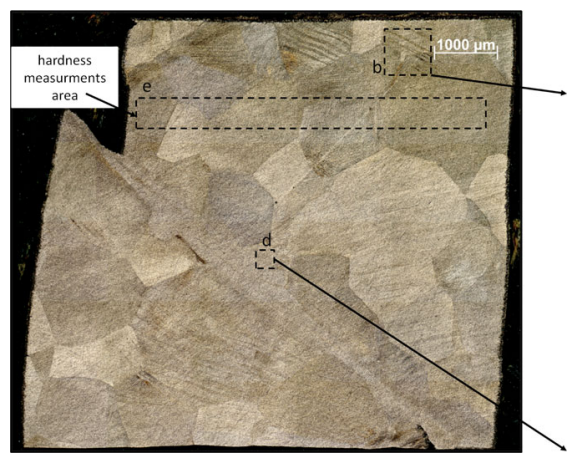

(a)

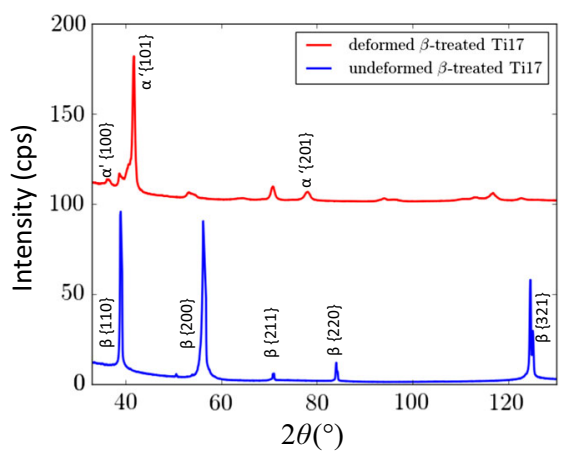

(c)

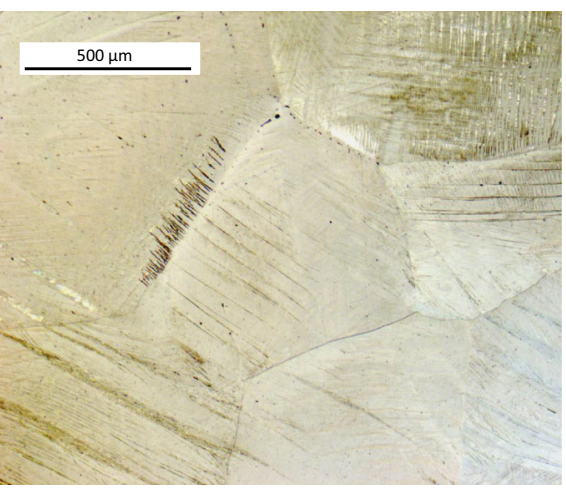

(b)

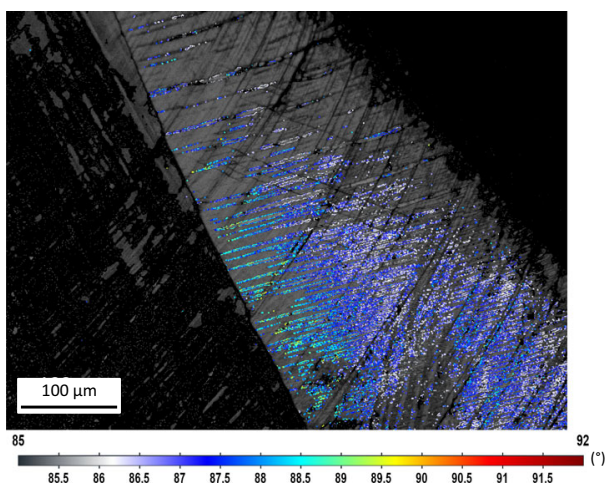

(d)

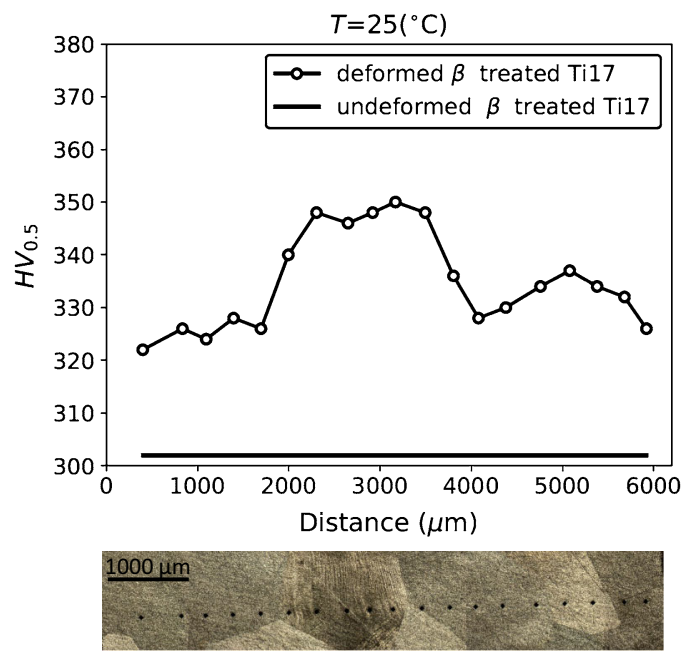

(e)

increase. The hardness increase is less significant for grains with little or no martensitic phase. This result is likely explained by the reduction of the mean free path of dislocations due to the formation of fine $\alpha^{\prime}$ martensite lamellae within $\beta$ grains.

For the $\beta$-treated microstructure, some ASBs are also observed on deformed specimens (see Fig. 13a). As shown in Table 4, in comparison with the as-received $\alpha+\beta$ microstructure, the $\beta$-treated microstructure is less prone to shear banding. Indeed, because of a higher strain-rate sensitivity, the formation of ASBs in the $\beta$-treated microstructure requires higher strain rates and lower temperatures. Indeed, because of a higher strain-rate sensitivity, the formation of ASBs in the $\beta$-treated microstructure requires higher strain rates and lower temperatures. The impact of strain-rate sensitivity on the formation of ASBs has been extensively reported in the 
literature [36, 47]. Specifically, a localization phenomenon, such as adiabatic shear banding, initiates when the strain rate significantly increases in some region of a specimen. For strain-rate-sensitive materials, the process leading to strain localization is easily interrupted as, for further localization to occur, the applied stress would have to increase significantly in the inhomogeneous deformation region. Strain-rate-sensitive materials are therefore less prone to shear banding.

Also, according to micro-hardness measurements, in contrast to the as-received $\alpha+\beta$ microstructure, the hardness within an ASB is higher than that of the surrounding $\beta$ matrix (see Fig. 14). A similar trend has been observed in [49-51]. At this stage, the reason for this behavior is unclear as neither EBSD analyses nor SEM observations have allowed determining the microstructure within the interior of an ASB.

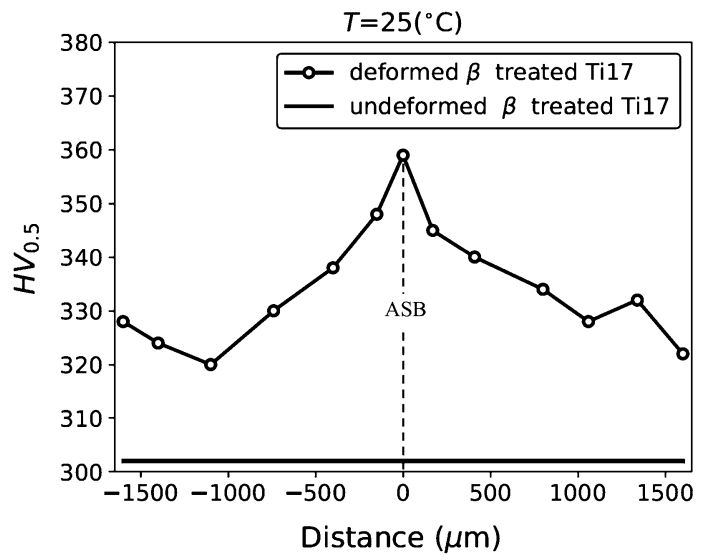

(a)

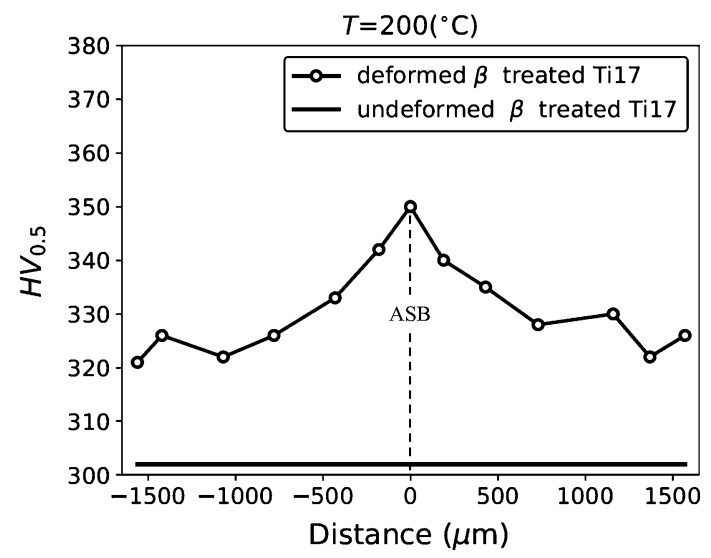

(b)

Figure 14 Evolution of the final Vickers hardness across an adiabatic shear band in a deformed $\beta$-treated Ti17 specimens at a strain rate of $10 \mathrm{~s}^{-1}$ and different temperatures.

\section{Conclusion}

The impact of the initial microstructure on the deformation behavior of the Ti17 titanium alloy has been investigated. In this perspective, uniaxial compression tests have been conducted on cylindrical specimens at strain rates ranging from 0.1 to $10 \mathrm{~s}^{-1}$ and temperatures ranging from 25 to $900{ }^{\circ} \mathrm{C}$. Two different microstructures have been considered: an $\alpha+\beta$ microstructure consisting of $\alpha$ lamellae being embedded in a $\beta$ matrix and a $\beta$-treated microstructure solely composed of equiaxed $\beta$ grains.

Whatever the loading conditions are, the flow stress behavior of the $\alpha+\beta$ microstructure is superior to that of the $\beta$-treated microstructure. Also, because of a lower strain-rate sensitivity, the $\alpha+\beta$ microstructure is more prone to shear banding. At low temperatures (i.e., $T \leq 450{ }^{\circ} \mathrm{C}$ ), the deformation behavior of both the as-received $\alpha+\beta$ and the $\beta$ treated Ti17 is controlled by strain hardening. For the $\beta$-treated Ti17 alloy, martensitic transformation is systematically detected in this temperature range. The softening behavior of the as-received $\alpha+\beta$ Ti17 observed at high temperatures is due to the joint effect of dynamic recrystallization, dynamic transformation, adiabatic heating and morphological texture evolution. For the $\beta$-treated Ti17 alloy, when the temperature exceeds $700^{\circ} \mathrm{C}$, stress-strain curves display a yield drop phenomenon, which are explained by dynamic recrystallization.

\section{Acknowledgements}

This research was supported by two French organizations from "Angers Loire Métropole": "Angers Loire Development" and "Angers Technopole." The authors would like to acknowledge their financial support.

\section{References}

[1] Arrazola P-J, Garay A, Iriarte L-M, Armendia M, Marya S, Le Maître F (2009) Machinability of titanium alloys (Ti6A14V and Ti555.3). J Mater Process Technol 209(5):2223-2230

[2] Boyer RR, Briggs RD (2005) The use of $\beta$ titanium alloys in the aerospace industry. J Mater Eng Perform 14(6):681-685. https://doi.org/10.1361/105994905X75448 
[3] Weiss I, Semiatin SL (1998) Thermomechanical processing of beta titanium alloys-an overview. Mater Sci Eng A 243(1):46-65

[4] Semiatin SL, Bieler TR (2001) The effect of alpha platelet thickness on plastic flow during hot working of Ti-6Al-4V with a transformed microstructure. Acta Mater 49(17):3565-3573

[5] Kolli RP, Arun D (2018) A review of metastable beta titanium alloys. Metals 8(7):2075-4701

[6] Semiatin SL, Seetharaman V, Ghosh AK (1999) Plastic flow, microstructure evolution, and defect formation during primary hot working of titanium and titanium aluminide alloys with lamellar colony microstructures. Philos Trans R Soc Lond Ser A Math Phys Eng Sci 357(1756):1487-1512

[7] Dawson AL, Blackwell P, Jones M, Young JM, Duggan MA (1998) Hot rolling and superplastic forming response of net shape processed $\mathrm{Ti}-6 \mathrm{Al}-4 \mathrm{~V}$ produced by centrifugal spray deposition. Mater Sci Technol 14(7):640-650

[8] Liu J, Zeng W, Lai Y, Jia Z (2014) Constitutive model of Ti17 titanium alloy with lamellar-type initial microstructure during hot deformation based on orthogonal analysis. Mater Sci Eng A 597:387-394

[9] Baoqi G, Semiatin SL, Jonas John J (2019) Dynamic transformation during the high temperature deformation of two-phase titanium alloys. Mater Sci Eng A 761:138047

[10] Momeni A, Abbasi SM (2010) Effect of hot working on flow behavior of Ti-6Al-4V alloy in single phase and two phase regions. Mater Des 31(8):3599-3604

[11] Delfosse J, Rey C, Spath N (2003) Polycrystalline modelling of forging in $\beta$ phase field of Ti 17. In: 10th World conference on titanium; Ti-2003 science and technology, pp 1315-1322

[12] Semblanet M, Pallot L, Piot D, Montheillet F, Derrien M, Millet Y, Poletti C, Desrayaud C (2016) Continuous dynamic recrystallization modeling in Ti-17 alloy: application to the forging operations in $\beta$ and $\beta+\alpha$ fields. In: Proceedings of the 13th world conference on titanium, pp 689-694

[13] Aeby-Gautier E, Settefrati A, Bruneseaux F, Appolaire B, Denand B, Dehmas M, Geandier G, Boulet P (2013) Isothermal alpha formation in beta metastable titanium alloys. J Alloys Compd 577:S439-S443

[14] Mu Z, Li H, Li MQ (2013) The microstructure evolution in the isothermal compression of Ti-17 alloy. Mater Sci Eng A 582:108-116

[15] Taku S, Andrey B, Rustam K, Hiromi M, Jonas John J (2014) Dynamic and post-dynamic recrystallization under hot, cold and severe plastic deformation conditions. Prog Mater Sci 60:130-207

[16] Ayed Y, Germain G, Ammar A, Furet B (2017) Thermomechanical characterization of the Ti17 titanium alloy under extreme loading conditions. Int $\mathrm{J}$ Adv Manuf Technol 90(5):1593-1603. https://doi.org/10.1007/s00170-016-94765

[17] Ning Y, Fu MW, Hou H, Yao Z, Guo H (2011) Hot deformation behavior of $\mathrm{Ti}-5.0 \mathrm{Al}-2.40 \mathrm{Sn}-2.02 \mathrm{Zr}-3.86 \mathrm{Mo}-$ $3.91 \mathrm{Cr}$ alloy with an initial lamellar microstructure in the $\alpha+\beta$ phase field. Mater Sci Eng A 528(3):1812-1818

[18] Li H, Li MQ, Han T, Liu HB (2012) The deformation behavior of isothermally compressed Ti-17 titanium alloy in $\alpha+\beta$ field. Mater Sci Eng A 546:40-45

[19] Zhao Z, Guo H, Wang X, Yao Z (2009) Deformation behavior of isothermally forged $\mathrm{Ti}-5 \mathrm{Al}-2 \mathrm{Sn}-2 \mathrm{Zr}-4 \mathrm{Mo}-4 \mathrm{Cr}$ powder compact. J Mater Process Technol 209(15-16):5509-5513

[20] Ma X, Zeng W, Sun Y, Wang K, Lai Y, Zhou Y (2012) Modeling constitutive relationship of Ti17 titanium alloy with lamellar starting microstructure. Mater Sci Eng A 538:182-189

[21] Huang B, Miao X, Luo X, Yang Y, Zhang Y (2019) Microstructure and texture evolution near the adiabatic shear band (ASB) in TC17 titanium alloy with starting equiaxed microstructure studied by EBSD. Mater Charact 151:151-165

[22] Zhang S, Zeng W, Zhao Q, Ge L, Zhang M (2017) In situ sem study of tensile deformation of a near- $\beta$ titanium alloy. Mater Sci Eng A 708:574-581

[23] Arab A, Chen P, Guo Y (2019) Effects of microstructure on the dynamic properties of Ta15 titanium alloy. Mech Mater 137:103121. https://doi.org/10.1016/j.mechmat.2019. 103121

[24] Jiang XQ, Fan XG, Li Q, Zhan M (2019) Strengthened flow instability in hot deformation of titanium alloy with colony structure: on the effect of microstructure heterogeneity. J Alloys Compd 801:381-393. https://doi.org/10.1016/j.jallc om.2019.05.179

[25] Zhao ZL, Li H, Fu MW, Guo HZ, Yao ZK (2014) Effect of the initial microstructure on the deformation behavior of Ti60 titanium alloy at high temperature processing. J Alloys Compd 617:525-533. https://doi.org/10.1016/j.jallcom.201 4.08 .092

[26] Wang K, Zeng W, Zhao Y, Lai Y, Zhou Y (2010) Hot working of Ti17 titanium alloy with lamellar starting structure using 3D processing maps. J Mater Sci 45(21):5883-5891. https://doi.org/10.1007/s10853-010-466 7-1

[27] Hull D, Bacon DJ (2011) Introduction to dislocations, 5th edn. Oxford University Press, Oxford

[28] Zhu Y, Zeng W, Zhao Y, Shu Y, Zhang X (2012) Effect of processing parameters on hot deformation behavior and 
microstructural evolution during hot compression of Ti40 titanium alloy. Mater Sci Eng A 552:384-391

[29] Wang X, Hamasaki H, Yamamura M, Yamauchi R, Maeda T, Shirai Y, Yoshida F (2009) Yield-point phenomena of Ti$20 \mathrm{~V}-4 \mathrm{Al}-1 \mathrm{Sn}$ at $1073 \mathrm{~K}$ and its constitutive modelling. Mater Trans 50(6):1576-1578. https://doi.org/10.2320/mate rtrans.M2009059

[30] Wu F, Xu W, Jin X, Zhong X, Wan X, Shan D, Guo B (2017) Study on hot deformation behavior and microstructure evolution of Ti55 high-temperature titanium alloy. Metals 7(8):319

[31] Ma X, Weidong Z, Kaixuan W, Yunjin L, Yigang Z (2012) The investigation on the unstable flow behavior of Ti17 alloy in $\alpha+\beta$ phase field using processing map. Mater Sci Eng A 550:131-137

[32] Cheng GM, Jian WW, Xu WZ, Yuan H, Millett PC, Zhu YT (2013) Grain size effect on deformation mechanisms of nanocrystalline BCC metals. Mater Res Lett 1(1):26-31. h ttps://doi.org/10.1080/21663831.2012.739580

[33] Sakai T, Jonas JJ (1984) Overview no. 35 dynamic recrystallization: mechanical and microstructural considerations. Acta Metall 32(2):189-209. https://doi.org/10.1016/0001-6 160(84)90049-X

[34] Li C, Zhang XY, Li ZY, Zhou KC (2013) Hot deformation of $\mathrm{Ti}-5 \mathrm{Al}-5 \mathrm{Mo}-5 \mathrm{~V}-1 \mathrm{Cr}-1 \mathrm{Fe}$ near beta titanium alloys containing thin and thick lamellar alpha phase. Mater Sci Eng A 573:75-83

[35] Semiatin SL, Jiangtao L, Binhan S, Jonas John J (2018) Opposing and driving forces associated with the dynamic transformation of Ti-6Al-4V. Metall Mater Trans A 49(5):1450-1454. https://doi.org/10.1007/s11661-018-4551-1

[36] Clifton RJ, Duffy J, Hartley KA, Shawki TG (1984) On critical conditions for shear band formation at high strain rates. Scr Metall 18(5):443-448

[37] Huang J, Geng L, Li AB, Cui XP, Li HZ, Wang GS (2009) Characteristics of hot compression behavior of Ti-6.5Al$3.5 \mathrm{Mo}-1.5 \mathrm{Zr}-0.3 \mathrm{Si}$ alloy with an equiaxed microstructure. Mater Sci Eng A 505:136-143. https://doi.org/10.1016/j.ms ea.2008.12.041

[38] Sandstrom R, Lagneborg R (1975) A model for hot working occurring by recrystallization. Acta Metall 23(3):387-398

[39] Rezaee M, Zarei-Hanzaki A, Mohamadizadeh A, Ghasemi E (2016) High-temperature flow characterization and microstructural evolution of Ti6242 alloy: yield drop phenomenon. Mater Sci Eng A 673:346-354

[40] Grosdidier T, Roubaud C, Philippe MJ, Combres Y (1997) The deformation mechanisms in the $\beta$-metastable $\beta$-Cez titanium alloy. Scr Mater 36(1):21-28
[41] Nwobu A (1982) Strain induced transformations and plasticity in transage $\mathrm{Ti}-11.6 \mathrm{~V}-2 \mathrm{Al}-2 \mathrm{Sn}-6 \mathrm{Zr}$ (T1134) and $\mathrm{Ti}-$ 11.5V-2Al-2Sn-11.3Zr (T129) alloys. J Phys Colloq 43:C4315-C4-320. https://doi.org/10.1051/jphyscol:1982444

[42] Ma X, Li F, Cao J, Li J, Sun Z, Zhu G, Zhou S (2018) Strain rate effects on tensile deformation behaviors of Ti-10V$2 \mathrm{Fe}-3 \mathrm{Al}$ alloy undergoing stress-induced martensitic transformation. Mater Sci Eng A 710:1-9

[43] Paradkar A, Kamat SV (2010) The effect of strain rate on trigger stress for stress-induced martensitic transformation and yield strength in Ti-18Al-8Nb alloy. J Alloys Compd 496(1):178-182

[44] Hamada AS, Karjalainen LP, Misra RDK, Talonen J (2013) Contribution of deformation mechanisms to strength and ductility in two $\mathrm{Cr}-\mathrm{Mn}$ grade austenitic stainless steels. Mater Sci Eng A 559:336-344

[45] Wei C, Shanshan Y, Ruolei L, Qiaoyan S, Lin X, Jun S (2015) Enhanced grain refining efficiency assisted by martensitic transformation in metastable beta-titanium alloy. Rare Met Mater Eng 44(7):1601-1606

[46] Grosdidier T, Philippe MJ (2000) Deformation induced martensite and superelasticity in a $\beta$-metastable titanium alloy. Mater Sci Eng A 291(1):218-223

[47] Hartley KA, Duffy J, Hawley RH (1987) Measurement of the temperature profile during shear band formation in steels deforming at high strain rates. J Mech Phys Solids 35(3):283-301

[48] Beausir B, Fundenberger JJ (2018) Atex software, analysis tools for electron and X-ray diffraction. University of Lorraine, Metz. www.atex-software.eu. Accessed 12 June 2019

[49] Zhan H, Zeng W, Wang G, Kent D, Dargusch M (2015) Microstructural characteristics of adiabatic shear localization in a metastable beta titanium alloy deformed at high strain rate and elevated temperatures. Mater Charact 102:103-113

[50] Duan CZ, Cai YJ, Wang MJ, Li GH (2009) Microstructural study of adiabatic shear bands formed in serrated chips during high-speed machining of hardened steel. J Mater Sci 44(3):897-902. https://doi.org/10.1007/s10853-008-3001-7

[51] Wang BF (2008) Adiabatic shear band in a Ti-3Al-5Mo4.5V titanium alloy. J Mater Sci 43(5):1576-1582. https://d oi.org/10.1007/s10853-007-2330-2

Publisher's Note Springer Nature remains neutral with regard to jurisdictional claims in published maps and institutional affiliations. 